\title{
Spain expands despite financial and logistical hurdles
}

\begin{abstract}
Madrid. Spain is hoping that money from industry and the European Communities will help it to expand research facilities in the provinces despite a shrinking national science budget and formidable administrative hurdles. Among the expected beneficiaries of that support are two institutes for plant biology and for food technology being built in Valencia and a cell and molecular biology institute that will soon open in Seville. But the fate of the newly inaugurated National Centre for Biotechnology $(\mathrm{CNB})$ in Madrid - whose opening was delayed for several years and which is still not fully functional - casts doubt on prospects for a smooth launch of the new centres of excellence.
\end{abstract}

Spanish science has made significant progress in the past 15 years, with an annual growth in budget of 18 per cent, to Pts600 billion (US $\$ 5$ billion). The early days of expansion spawned the concept of building world-class centres of excellence, including the National Centre for Microelectronics in Barcelona, which opened in 1990 , and the $\mathrm{CNB}$, which began operations last September.

This growth has occurred despite the continuing concentration of scientific funds and personnel in Madrid and Barcelona. For example, in 1988 only a third of all research funds from the Ministry of Health went to the rest of the country. The Spanish government, determined to change this pattern, decided with Spain's research council (CSIC) to build institutes outside the two major cities with money from other sources. Both institutes in Valencia were built with funds obtained from the European Commission (EC) on land donated by the local university. The Seville Institute, now called the Andalusian Laboratory of Biology, hopes to get money from the EC as well as from the regional government of Andalusia.

The new institutes hope to avoid the problems that have beset the biotechnology institute, which has suffered from the ingrained inefficiencies resulting in part from a shift from the highly centralized adminis-

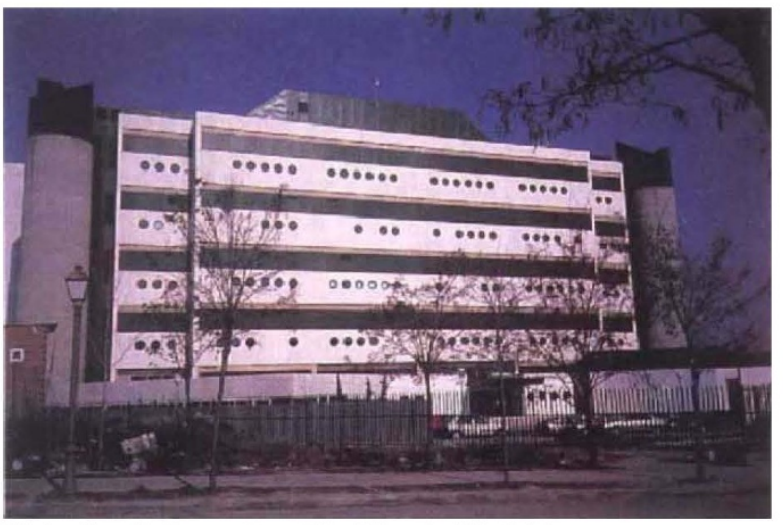

Biotechnology centre struggles in Madrid. tration in the early 1980 s to a more complicated bureaucracy that provides local and regional administrations as well as universities with their own budgets. The CNB must deal with all three parties.

CNB's first director, the Spanish-speaking, British-born biologist Michael Parkhouse, resigned in 1990 after four years because of the delays and the related uncertainties of his one-year contracts. The same problems precipitated the resignation after two years of the second director, José López Carrascosa. Both men complained of the time spent on arranging for continued funding for the centre.

The appointment of scientific staff is another major problem for the CNB. Although the system was created to ensure a degree of autonomy from CSIC, tenured laboratory chiefs (of whom there will be 36 ) must be approved first by a scientific advisory board, then by a national board with representatives of government and industry, and finally by CSIC itself. Once appointed, laboratory chiefs face the uncertainty of having their scientific plans altered by layers of bureaucracy. (The selection of ten of these positions has been postponed until new scientific advisory boards have been established.)

The current director, Mariano Esteban, a molecular biologist appointed last August, is well aware of these problems, with two department chiefs - each responsible for eight laboratories - having resigned in the past few weeks in disputes over scientific priorities and staff appointments. Francisco Malpartida, who was chief of CNB's department of microbiology, says that "some primary research lines suddenly became very low priority and so scientists who had previously been appointed could not join the centre".

Discontent also extends further down the ranks. Marisa Toribio, a CSIC investigador - - the first step towards tenure - - was offered a post as laboratory chief but has decided to remain in an institute near the CNB. She says the move would have restricted her scientific independence and left her with an uncertain future.

Esteban must also grapple with the effects of the recession, which has led to cuts in the Spanish science budget and a freeze on all civil service appointments for 1993. The centre's operating budget, originally expected to reach Pts500 million, has been reduced and runs out in summer, and industrial support is being sought. The ban on new appointments has cre- ated a situation in which the centre, the most modern and sophisticated in Spain with facilities for 350 scientists, stands virtually idle for want of the necessary technical support.

Officials at the three new institutes say they have learned from CNB's troubles. "We will try to avoid a complicated decision-making processes at all levels," says Enrique Cerdá, a university professor in Seville who is helping to set up the cell and molecular biology institute. "Researchers will be recruited only on scientific merit and appointments will be reviewed on a fiveyear basis [instead of those concerned being offered tenure]."

Cerdá has a good chance of success because his institute is at present independent of CSIC, but the Valencia institutes must abide by CSIC rules. Last year, for example, CSIC offered only 78 tenured positions for its hundred institutes, making it unlikely that the Valencia institutes will get "the [necessary] input of fresh scientific persons and ideas", says Daniel Ramón, an investigador who is moving to one of the new institutes.

Despite these problems, Spanish scientists still expect to have as much autonomy as their counterparts in other European countries. And they remain convinced that the new facilities will in the long run raise the quality of Spanish science.

Oscar G. Segurado

\section{Station redesign clouds NASA budget for space science}

Washington. The amount of funding available next year for several proposed new space science and technology projects from low-cost planetary missions to small Earth probes and lunar orbiting spacecraft - awaits a decision by the US National Aeronautics and Space Administration (NASA) and its international partners on the redesign of space station Frecdom (see Nature 362, 484; 1993).

President Bill Clinton's budget released last week includes a request for $\$ 15.625$ billion for NASA in fiscal year 1994, with a total of $\$ 2.3$ billion for the station and for new science and technology initiatives. Last autumn, Congress appropriated $\$ 2.2$ billion in 1993 for the station alone. The White House has ordered NASA to study three options for building the station - with costs of $\$ 5$ billion, $\$ 7$ billion or $\$ 9$ billion over five years - and to consider building it jointly with Russia. Until the redesign is complete, however, the space agency will not know how much is left for new projects.

Tony Reichhardt 